\title{
Education Options in Rehabilitation Counselling
}

The development of University level rehabilitation counselling programs in Australia has been a steady and consolidated process over 25 years. For much of the early curriculum development, support and assistance was sought from well established programs in the Unites States and this relationship proved to be a useful and valid exercise and to some extent is continuing. Although Australian programs clearly strive to meet Australian challenges, the increasingly fluid nature of education, training and on-going professional development means that elements of programs are not necessarily restricted to the prime provider who may or may not have the expertise and resources to provide those elements.

Many education and training providers are using web based platforms to provide teaching and training platforms that are not constrained by geography and time. Australian training institutions are increasingly examining such options and many have implemented them. Despite some recent evidence that on-line learning may not be the panacea that was first thought, there seems sufficient utility in internet platforms to enable a portion at least of most courses and training modules to be undertaken through the web. Once the initial information technology investment is recouped, the cost benefits would appear obvious to most parties. How can this work in rehabilitation education?

On a recent trip to the United States I had the opportunity to meet with the Professors of the Master's degree in rehabilitation counselling at Utah State University at Logan, Utah. Both Garth Eldredge and Julie Smart have developed and teach in that University's distance education online program as well as in the internal program. Initially Zan Merrill, the RCE program Manager, researched available "virtual classroom" technology and the program went ahead with a system by Rotor Communications. Students join the class in real time via their own computer and the Rotor program enables split screen functionality to see the lecturer/speaker, receive Powerpoint, audio and video presentations. Presently there are two chat features that enable students to synchronously communicate by type with the lecturer, but two way audio is imminent. Other features are the use of smart whiteboard touch-screen technology and instant answers to questions and quizzes. The program currently schedules at least one session per week with distance students using this technology and supplements it with mail outs of traditional print and disk based learning material as well as teleconferences. There is also a requirement that a minimum number of courses in the program must be taken as an internal student, but that can mean that the lecturer goes to the students off site if it is more efficient that way. Early indications are that the program is well accepted by the student body and is being closely examined by other masters program in the United States.

Whilst there are numerous virtual classrooms programs, most including Rotor strive to enable the best possible two way communication via generally accessible personal computers. Guest lectures in Australian rehabilitation programs and in professional development seminars are economically accessible from overseas individuals in real or 
delayed time. There is a great deal of potential for a professional society such as ASORC to access such expertise via this increasingly available technology. Aside from perhaps inviting one or several guest speakers at national conferences to participate in this way, it will be a useful technology to develop professional development or continuing education opportunities and access a range of experts at reduced cost.

This issue contains a set of articles which are I believe of great relevance to rehabilitation counselling. In the lead article Lindsay Gething examines aspects of ageing with an intellectual disability. The article reports on an Australian project which conducted extensive consultations with people with disabilities and their advocates, and representatives form community and government agencies. The resultant findings are described under several themes for coherence and argue for service provider and funder collaboration and planning under a broad banner of personal empowerment for those ageing with an intellectual disability.

Cathie Collinson and her colleagues examine the relations between organisational perceptions, personal evaluations, and job satisfaction among a group of rehabilitation case managers. Other authors (e.g., Cranswick, 1997, and Onyett, Pillinger \& Muijen, 1997) have reported that human service workers overall report being satisfied with their jobs in the rehabilitation field, but the authors in this article caution that this could be due to the "resilience" of such workers who maintain services and standards in an increasingly challenged resource environment. They argue their findings support previous research that suggests increases in job satisfaction provide a more motivating and productive environment which in turn better supports the goals of the provider and the consumer alike.

An examination of the impact of physical disability on gardening activities in mid-aged women examines the well researched link between horticultural activity and positive patient impact in a variety of settings. An important finding of this study is that those clients with physical disabilities were in the main able to pursue gardening activities of a type and level not significantly different from other midaged women without physical limitations. Given that horticulture is one of the most popular leisure activities, and one well used in many rehabilitation programs, this suggests it will remain an accessible, valuable and appropriate therapeutic intervention for the majority of people.

Harry McNaughton and Kathryn McPherson provide readers with a current overview of New Zealand's Accident Compensation system. The scheme was once well known for a unique 24 hour comprehensive coverage and minimal legal liability. Since being introduced in 1974, it remained relatively stable until the 1990 's. Since that time a number of changes have occurred to the scheme which have substantially altered it's nature. The authors' provide a contemporary overview with commentary of interest to Australian rehabilitation providers.

The final article will perhaps not be without controversy. Debra Jackson reports on a study of compulsivity which she has termed "cybersex addiction". She argues that internet addiction per se, and cybersex addiction in particular is a phenomena of increasing concern for health professionals. The burgeoning increase of web based pornography sites and increasing use of anonymous chat rooms, coupled with ready access at home and in the workplace to web-linked personal computers, has provided liberal opportunities for interaction and subsequent compulsivity. There are important industrial relation issues for both employer and employee, and current legislation is inadequate. Initial data suggests any employer response, if any, is gener- 
ally punitive with little thought to longer term solutions. Such addictions are likely to increase rather than decrease, and rehabilitation counsellors are well placed to gain the necessary skills to assist clients and advise employers on appropriate therapeutic interventions.

This is the last issue for 2000. It's been a year of great excitement and national pride in the achievements of all in the Sydney Olympics and Paralympics. On behalf of the Associate and Consultant Editors, and the support staff of the Journal, may I extend the compliments of the season and wish a safe and happy Christmas/New Year break to all readers of the Journal.

Herbert C. Biggs Ph.D, Editor 
